\title{
Inhalt
}

\section{Karl Möckl}

Wirtschaftsbürgertum im 19. und beginnenden 20. Jahrhundert.

Einleitung

\section{Friedrich-Wilhelm Henning}

Das Wirtschaftsbürgertum in einer Agrarregion im 19. Jahrhundert, dargestellt am Beispiel Ostpreußen

\section{Harm-Hinrich Brandt}

Das Wirtschaftsbürgertum Österreichs von den Anfängen

der Industrialisierung bis 1848

Helmut Böhme

Berliner Finanzbürgertum im 19. Jahrhundert

Fritz Hellwig

Das Wirtschaftsbürgertum an der Saar im 19. Jahrhundert

Franz Fischer

Das Wirtschaftsbürgertum des Rhein-Main-Gebiets im 19. Jahr-

hundert. Ein Beitrag zur historischen Mobilitätsforschung....

Peter Fassl

Wirtschaftliche Führungsschichten in Augsburg 1800-1914

Klara van Eyll

Kölns Wirtschaftsbürgertum im 19. Jahrhundert (bis 1914)

Rainer Gömmel

Das Nürnberger Wirtschaftsbürgertum im 19. Jahrhundert

Gerhard Hirschmann

Die Bedeutung des Konnubiums, aufgezeigt an Beispielen aus dem Nürnberger Wirtschaftsbürgertum im 19. Jahrhundert.

Dirk Schumann

Wirtschaftsbürger und Wirtschaftsbürgertum in Regensburg im

19. Jahrhundert 
Ernst Bruckmüller/Wolfgang Meixner

Wiener Wirtschaftsbürgertum um 1900. Methodische Vorüberlegungen zur Erforschung und Darstellung einer sozialen

Gruppierung

\section{Jürgen Schneider}

Wirtschaftsbürger und Unternehmer. Die Bedeutung von Produkt und Ausbildung am Beispiel der Chemischen Industrie Deutschlands um 1900

Francesca Schinzinger

Die Familie Perrot: „Wirtschaftsbürger“ in den deutschen Kolonien

Michael Stürmer

Männer von Verdienst und Vermögen: Die Bankiers Simon und Abraham von Oppenheim

Johannes Cramer

Fabrikantenvillen

Personenregister 